\title{
Multitemporal land use changes in a region of Pindus mountain, central Greece
}

\author{
Apostolos Ainalis ${ }^{1}$, Ioannis Meliadis ${ }^{2}$, Konstantinos Tsiouvaras ${ }^{3}$, Katerina Ainali ${ }^{4}$, Dimitrios Platis ${ }^{5}$, \\ Panagiotis Platis ${ }^{6}$ \\ ${ }^{1}$ Directorate of Coordination and Inspection of Forests, Decentralised Administration Macedonia-Thrace, 46th Agriculture School St, \\ Thessaloniki \\ ${ }^{2}$ Lab. of Remote sensing and GIS, Forest Research Institute, N.AG.RE.F., Vassilika, Thessaloniki \\ ${ }^{3}$ Laboratory of Range Management (236), Dept. of Forest and Natural Environment, Aristotle University of Thessaloniki, Thessaloniki \\ ${ }^{4}$ Lab. of Geoinformatics, Rural and Surveying Engineering, National Technical University of Athens, Zografou Campus, Iroon Polytechniou 9, \\ Athens \\ ${ }^{5}$ Lab. of Ecology, Dept. of Agriculture, Aristotle University of Thessaloniki, Thessaloniki \\ ${ }^{6}$ Lab. of Range science, Forest Research Institute, N.AG.RE.F., Vassilika, Thessaloniki
}

\section{Email address:}

aainalis@hotmail.com (A. Ainalis), meliadis@fri.gr (I. Meliadis), tsiouvar@for.auth.gr (K. Tsiouvaras), kainali30@gmail.com (K. Ainali), dimitris_pl@hotmail.com (D. Platis),pplatis@fri.gr (P. Platis)

\section{To cite this article:}

Apostolos Ainalis, Ioannis Meliadis, Konstantinos Tsiouvaras, Katerina Ainali, Dimitrios Platis, Panagiotis Platis. Multitemporal Land Use Changes in a Region of Pindus Mountain, Central Greece. Agriculture, Forestry and Fisheries. Vol. 4, No. 1, 2015, pp. 18-23.

doi: $10.11648 /$ j.aff. 20150401.14

\begin{abstract}
Natural ecosystems are renewable resources with special environmental, social and economical attributes and characteristics. The increasing need of the human beings for a better environment leads to the use of new technologies that offer many advantages in detecting changes in the ecosystems. In this study the integration of remote sensing tools and technology and the spatial orientation analysis of Geographical Information Systems (G.I.S.) combined with in situ observations were used in determining any changes in land cover categories along an 18 year period. The study area of 9,287 ha extends to Pindus mountain, in the municipality of Plastira, central Greece. The results have shown that the current technologies can be used for the modelling of environmental parameters improving our knowledge on its attributes, characteristics, situation, trends and changes of natural ecosystems. The multitemporal changes that were observed are mostly due to vegetation evolution and less to socioeconomic reasons. The basic management strategy for the specific area should combine forest, pasture and livestock in such a way that each component produces usable products, while in the same time preserves sustainability.
\end{abstract}

Keywords: G.I.S., Image Processing, Multitemporal Analysis, Range Management, Land Use, Livestock Fluctuation

\section{Introduction}

The internal observation of vegetation changes requires a series of parameters which can be met not only with terrestrial methods of the landscape observation, but also with the use of remote sensing and digital image processing. All these, offer the possibility of developing and applying methods and techniques for studying environmental problems and phenomena of monitoring changes in vegetation cover classes, specifically in areas with significant importance to nature conservation. The changes in these characteristics can be recorded over time in order to understand the multitemporal dynamics. To perceive this objective, we must first identify the vegetation classes and the land use at the reference time. Moreover, an important element in the temporal classification of vegetation is the livestock fluctuation. The reduction or increase of grazing animal number differentiates succession of vegetation, bringing about positive or negative results (Noitsakis et al. 1992, Milchunas 2006).

A wide range of remote sensing and G.I.S. applications in geotechnical sciences refers to multitemporal studies (Richards 1993, Lillesand and Kiefer 1994). Examples of applications in environmental studies refer to land cover changes (Chavez and MacKinnon 1994, Mas 1999, Houvardas et al. 2001, Ainalis et al. 2006, Ainalis et al. 2007, Platis et al. 2009), forest fires and deforestation (Kuntz and 
Karteris 1993), coastal changes in the prefecture of Magnesia, Greece (Perakis et al. 1997), habitat changes of protected areas (Meliadis et al. 2004, Platis et al. 2004) and rangelands inventory (Platis et al. 2001). Various evaluation methods have been proposed by researchers on the assessment of land cover changes (Sunar 1998, Mas 1999, Wrbka et al. 1999).

The purpose of this study was the recording of multitemporal land use changes, especially vegetation changes, in the area of the municipality of Plastira and specifically in Pindus mountain, central Greece, using satellite images and in situ observations.

\section{Materials and Methods}

The study was conducted in an area of Pindus mountain, located in the municipality of Plastira, central Greece (Fig. 1). It extends from $200 \mathrm{~m}$ to $1,200 \mathrm{~m}$ above sea level and its largest part is covered with grasslands, shrublands and broadleaf forests.

The survey has covered an area of 9,287 ha in the west southwestern part of Karditsa prefecture, located at the north side of Lake Plastiras. Part of the study area is designated as a Special Protection Area (SPA).

The prevailing parent rocks in the study area are colluvium shale located around the lake. These are deposits of the Tertiary period in the lowland areas and flysch in the other regions (Barntovas and Rantogianni - Tsiampaou 1983). The soil is sandy-clay and clay with moderate organic matter (Nakos 1977). The climate is continental with cold, rainy and several times snowy winters and hot, dry summers (Mavrommatis 1980).

Information concerning the annual rainfall for the period 1989 - 2007 were taken from the nearest meteorological station of Kalambaka region situated at an altitude of 450 meters (60 km NW of the municipality of Plastira) (H.N.M.S. 2013). The region belongs to the Mediterranean mountain ecological zone (Quercetalia pubescentis) (Dafis 1973).

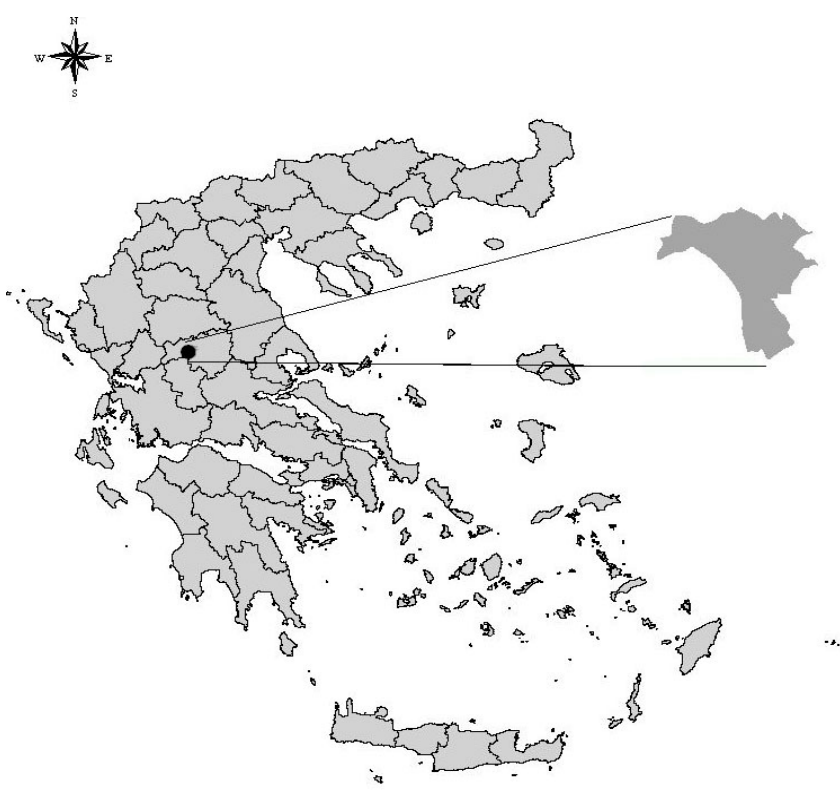

Figure 1. General map of the study area in Pindus mountain, central Greece.

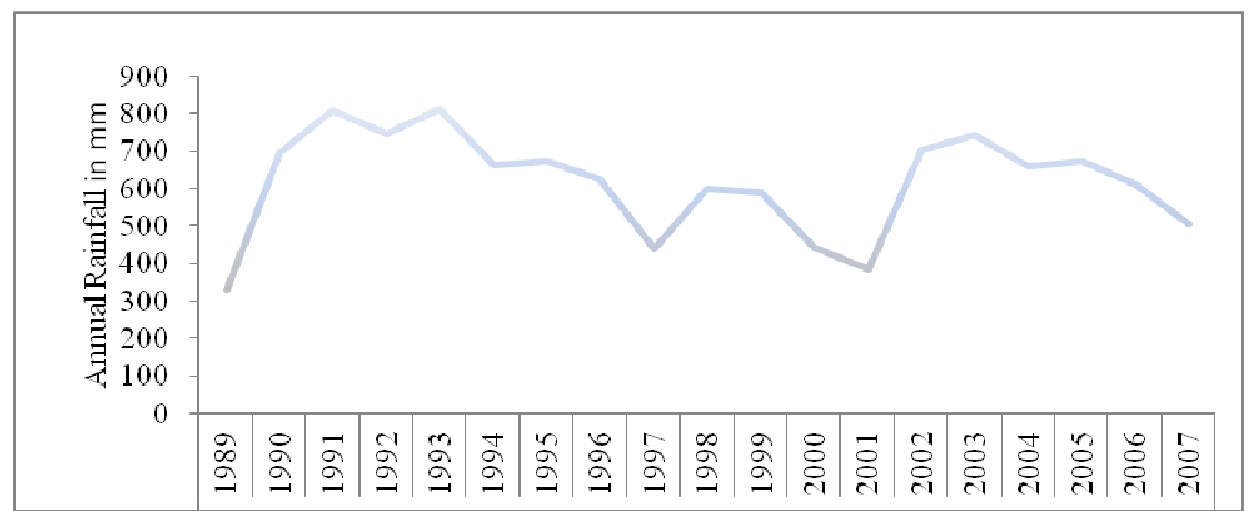

Figure 2. Annual rainfall in the period 1989 - 2007 from the meteorological station of Kalambaka in central Greece.

The data sources used are from satellite images that were taken at three different times, during an 18 year period: in 1989, 2000 and 2007. The images of 1989 were obtained from the satellite LANDSAT 5 TM (Thematic Mapper) with code $184-033$ and date July16, 1989, while the images of 2000 were obtained from the newest satellite LANDSAT 7 ETM+ (Enhanced Thematic Mapper Plus) with code 184 - 032 and date May 02, 2000. Finally, images of 2007 were obtained from the satellite LANDSAT 7 ETM with code 184 - 033 and date June 24, 2007 (Fig. 3).

The following vector and point data such as: roads, hydrographical network, contour lines, boundaries settlement, and local names were used as auxiliary elements. The recording was at an average scale $(1: 50,000)$ detailing the corresponding pixel size of the satellite images used (30x30m).

The methodology was distinguished in four separate stages: a) the preliminary processing of satellite data (corrections, georeference, etc), b) the classification of satellite data, c) the detection of temporal changes and d) the use of a Geographic Information System (G.I.S.), namely ArcGis 9.3 for the processing of the maps. In the final stage of the investigation, the thematic maps generated by the second stage combined with the results of temporal changes in a common geographic database. 


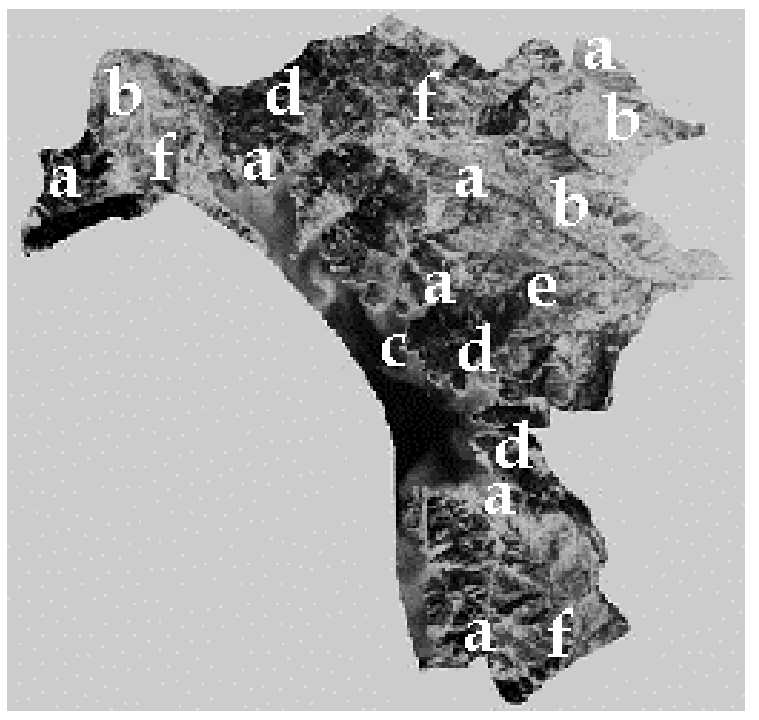

Figure 3. Satellite image processing for the year 2007 showing vegetation changes in the study area of Pindus mountain, central Greece (a: rangelands, $b$ : agricultural lands, c: lake surface, $d$ : forests, e:urban areas , $f$ : flooded lands).

The images were geometrically rectified and registered to the same projection namely GGRS87 (Greek Grid Reference System) to lay them over each other.

The initial (1989) the middle (2000) and final (2007)
Landsat imageries were subjected to a classification of zones. Supervised classification was utilized to classify the images to different land use categories.

The classification of the 1989 image was collated with the images of 2000 and 2007 and then the classification application of the majority filter was followed (Meliadis et al. 2009). Finally, the maps of the three years $(1989,2000$ and 2007) were compared, using as reference year the 2007. Ground-based observations were taken in situ during 2007. Livestock numbers, animal species, grazing period, grazing system, shed position, site quality and range condition were recorded and then marked on maps. Range condition was classified following the criteria on table (1) (Papanastasis 1989).

The sheep and goats were the main livestock species grazing in the study area. A few cattle were also grazing in this area, but cattle farming were mostly limited. Grazing was performed for seven months per year, following a traditional continuous grazing system. The average stocking rate in the study area was estimated as the number of small ruminants per ha. One cattle was assumed equal to five small ruminants (Holechek et al. 1989). Grazing capacity was evaluated taking into account the dry matter production of the rangelands, the total rangeland area and the forage needs of domestic animals (Athanasiou et al. 2007).

Table 1. Criteria for range condition classification (After Papanastasis 1989).

\begin{tabular}{|c|c|c|c|c|c|}
\hline \multirow{2}{*}{ Class } & \multirow{2}{*}{ Desirable plants } & \multirow{2}{*}{ Vegetation cover } & \multicolumn{2}{|c|}{ Shrub characteristics } & \multirow{2}{*}{ Erosion } \\
\hline & & & High & Cover & \\
\hline Good & $\geq 70 \%$ & $\geq 2 / 3$ & $\leq 1 \mathrm{~m}$ & $\leq 40 \%$ & No evidence of erosion \\
\hline Fair & $40 \%-70 \%$ & $1 / 3-2 / 3$ & $\leq 1 \mathrm{~m}$ & $\leq 70 \%$ & No evidence of accelerated erosion \\
\hline Poor & $<40 \%$ & $<1 / 3$ & $\geq 1 \mathrm{~m}$ & $\geq 70 \%$ & Signs of accelerated erosion \\
\hline
\end{tabular}

\section{Results and Discussion}

Livestock capital in the area was averaged to 8,200 small animal units, during the period of 1994 to 2008, with a mean grazing pressure of 0.18 a.u.m./ha on land available for grazing, while the grazing capacity did not exceed 0.14 a.u.m./ha for seven months grazing (Athanasiou et al. 2007).

The majority of rangelands in the study area were classified in fair condition (Table 2). Especially, in the grasslands, some desirable plant species for livestock (Festuca valesiaca Schleich.; Poa bulbosa, L.; Trisetum flavescens, (L) Beauv.; Trifolium hirtum, All.; T. campestre, Schreb.; T. nigrescens, Viv.; T. glomeratum. L.; T. angustifolium, L.; Medicago minima, Crufb.; M. lupulina. L.; Vicia sativa, L.) participated in relatively low percentages in the vegetation composition (Athanasiou et al. 2007). A significant part of the total rangeland area was in poor condition $(28 \%)$ with signs of accelerated erosion, especially in high altitudes and steep slopes (Table 2). Only 9\% of the total rangelands were classified in good condition and were present mainly in medium elevated sites with slopes not exceeding $15 \%$.

The prevailing site quality in the rangelands was site class I and II (Table 3). The $62 \%$ of the rangelands in the study area was classified as site class I having a deep soil $(>30 \mathrm{~cm})$ (Table
3), 33\% was classified as site class II (with soil depth between $15-30 \mathrm{~cm})$, while the rest area was classified as site class III (Table 3).

Table 2. Range condition classes in the study area of Pindus mountain.

\begin{tabular}{lcr}
\hline \multirow{2}{*}{ Range class } & \multicolumn{2}{c}{ Area } \\
\cline { 2 - 3 } & ha & \multicolumn{1}{c}{$\%$} \\
\hline Good & 131.36 & 9.00 \\
Fair & 919.47 & 63.00 \\
Poor & 408.65 & 28.00 \\
Total & $1,459.48$ & 100.00 \\
\hline
\end{tabular}

Table 3. Site quality classes in the rangelands in the study area of Pindus mountain

\begin{tabular}{lrr}
\hline \multirow{2}{*}{ Site class } & \multicolumn{2}{c}{ Area } \\
\cline { 2 - 3 } & ha & \% \\
\hline I* & 904.88 & 62.00 \\
II & 481.62 & 33.00 \\
III & 72.98 & 5.00 \\
Total & $1,459.48$ & 100.00 \\
\hline
\end{tabular}

* I: soil depth $>30 \mathrm{~cm}$, usual slope $<15 \%$, II: soil depth $15-30 \mathrm{~cm}$, usual slope $15-30 \%$, III: soil depth $<15 \mathrm{~cm}$, usual slope $>30 \%$

The monitoring implementation has shown that the dominant vegetation for livestock grazing was classified in the 
type of evergreen broadleaf shrublands, followed by the abandoned fields, the grasslands and the grazed open forests. The area changes in hectares per land use category over the years are shown in table (4). An increase in the coverage of land uses was recorded at the end of the study period for the categories of grasslands (158.3\%), forests (14.9\%), agricultural land $(14.4 \%)$, lake water surface $(10.2 \%)$ and the urban areas (17.7\%), corresponding to a decrease recorded for the categories of abandoned fields (67.2\%), evergreen broadleaf shrublands $(37.5 \%)$, grazed open forests $(68.3 \%)$ and barren areas (61\%) (Table 4$)$. The forests covered $46 \%$ of the total area and were mainly coppice forests of deciduous broadleaf species, such as Quercus conferta, Kit. and $Q$. petraea, L. (Q. sessiliflora, S.) (Table 4).
Table 4. Land uses (in ha) in the study area of Pindus mountain, central Greece, during the period 1989 - 2007.

\begin{tabular}{lrrr}
\hline \multirow{2}{*}{ Land use categories } & \multicolumn{3}{c}{ Years } \\
\cline { 2 - 4 } & $\mathbf{1 9 8 9}$ & $\mathbf{2 0 0 0}$ & $\mathbf{2 0 0 7}$ \\
\hline Rangelands & 1933.63 & 1502.04 & 1459.48 \\
Abandoned fields & 485.12 & 292.28 & 158.89 \\
Grasslands & 231.09 & 321.03 & 596.93 \\
Evergreen Shrublands & 1031.10 & 775.88 & 644.63 \\
Grazed Open Forests & 186.32 & 112.85 & 59.03 \\
Forests & 3723.12 & 4089.27 & 4277.45 \\
Other Areas & 3630.26 & 3695.70 & 3550.08 \\
Agricultural lands & 2159.90 & 2323.25 & 2470.00 \\
Flooded lands & 761.12 & 605.18 & 296.71 \\
Lake surface & 690.12 & 744.97 & 760.87 \\
Urban areas & 19.12 & 22.30 & 22.50 \\
Total & 9287.01 & 9287.01 & 9287.01 \\
\hline
\end{tabular}

Table 5. Multitemporal land use differences (positives and negatives) (in ha) between the years 1989-2000, 2000-2007 and 1989-2007.

\begin{tabular}{|c|c|c|c|c|c|c|}
\hline \multirow{2}{*}{ Land cover categories } & \multicolumn{2}{|c|}{ Differences between 1989 - 2000} & \multicolumn{2}{|c|}{ Differences between 2000 - 2007} & \multicolumn{2}{|c|}{ Differences between $1989-2007$} \\
\hline & Positive & Negative & Positive & Negative & Positive & Negative \\
\hline Rangelands & 89.94 & -521.53 & 275.90 & -318.46 & 365.84 & -839.99 \\
\hline Abandoned fields & & -192.84 & & -133.39 & & 326.23 \\
\hline Grasslands & 89.94 & & 275.90 & & 365.84 & \\
\hline Evergreen Shrublands & & -255.22 & & -131.25 & & 386.47 \\
\hline Grazed Open Forests & & -73.47 & & -53.82 & & 127.29 \\
\hline Forests & 366.15 & & 188.18 & & 554.33 & \\
\hline Agricultural lands & 163.35 & & 146.75 & & 310.10 & \\
\hline Flooded lands & & -155.94 & & -308.47 & & 464.41 \\
\hline Lake surface & 54.85 & & 15.90 & & 70.75 & \\
\hline Urban areas & 3.18 & & 0.20 & & 3.38 & \\
\hline Total & 677.47 & -677.47 & 626.93 & -626.93 & 1304.40 & -1304.40 \\
\hline
\end{tabular}

Throughout the period of 18 years $(1989-2007)$ the land uses were diversified (Table 5). Among the increased land uses, forests contributed by $54 \%$ to the increase for the period $1989-2000$, by $30 \%$ for the period $2000-2007$ and by $42.5 \%$ for the whole period of 1989 - 2007 (Table 5). These changes were probably due to the gradual decline of transhumance grazing in mountain areas (Fig. 2).

More specifically, the gradual decrease of sheep number (19.8\%), especially during the period between 2000 and 2008 (Fig. 4) as well as the gradual decrease of goats (26.7\%) for the whole period (Fig. 2), contributed to the decrease of grazing pressure especially in the shrublands. As a result the evergreen shrublands were grown in height and thicken taking the form of forests contributing to the increase of the forest area (Papanastasis 2003, Athanasiou et al. 2007). The decrease of evergreen shrublands contributed by $37.7 \%$ and $20.9 \%$, respectively, to the total negative change of land use area in the two periods $(1989-2000)$ and $(2000-2007)$ and by $29.6 \%$ as a total for the whole period (Table 5 ).

The increase of agricultural land use contributed by $24.1 \%$ and $23.4 \%$, respectively, to the total positive change of land use area in the two periods $(1989-2000$ and $2000-2007)$ or $23.8 \%$ for the whole period (Table 5). The increase of agricultural land was mainly due to the reduction of the abandoned fields, which was in a large degree a result of the return of land owners back to farming.

The reduction of the abandoned fields contributed by $28.5 \%$ and $21.3 \%$, respectively, to the total negative change of land use area in the two periods (1989 - 2000 and $2000-2007)$, and by $25 \%$ as a total for the whole period (Table 5 ).

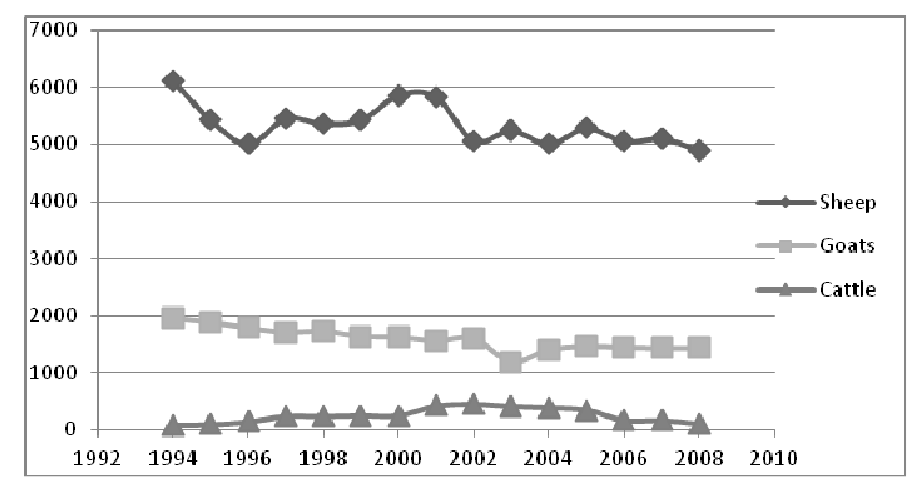

Figure 4. Multitemporal annual changes of animal number, grazing in the study area of Pindus mountain, central Greece, during the period of 1994-2008. 
The increase of grasslands contributed by $13.3 \%$ and $44 \%$, respectively, to the total positive change of land use area in the two periods (1989 - 2000 and $2000-2007)$ and by $28 \%$ as a total for the eighteen years period. This probably happened due to the reduction of annual rainfall in the region within the period of 2000 and 2007 (Fig. 2) and the withdrawal of flooded soils which led to the increase of grasslands (Fig. 5). The reduction of grazed open forests by $10.8 \%$ and $8.6 \%$ during the two periods and by $9.8 \%$ as a total for the whole period (Table 5) was due to the restoration of density and growth in height of deciduous broadleaf species. This forest restoration was favored by the gradual decrease of grazing animal number, especially, in mountainous areas (Table 4 and 5). Furthermore, an increase of $8.1 \%$ and $2.5 \%$ in lake water surface was recorded, which is probably attributed to the date (early May 2000) of receiving the satellite imagery (moving along the shoreline of the lake during the year).

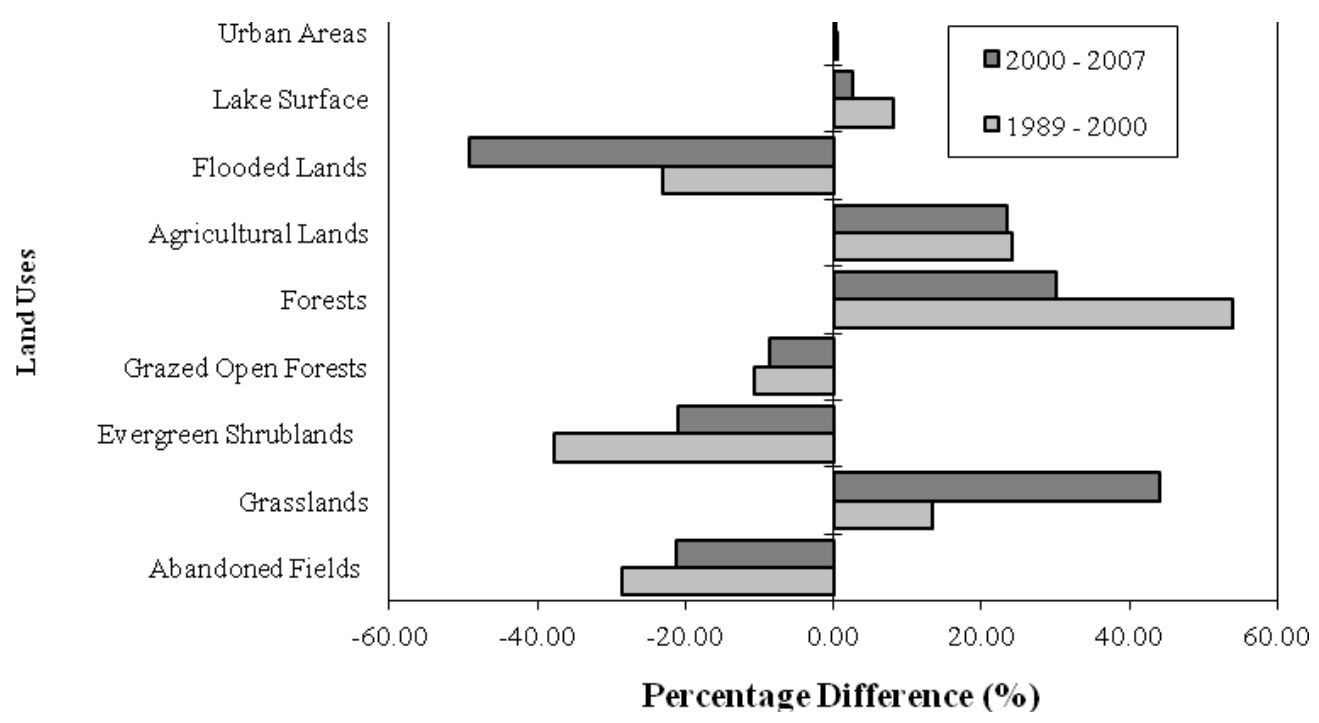

Figure 5. Land use changes (\%) in the study area of Pindus mountain, central Greece in the periods 1989 - 2000 and 2000 - 2007.

Overall, the reduction of total grazing areas as a part of an overall reduction of land uses accounted to $63.7 \%$ in the first period (1989 - 2000) and to $6.8 \%$ in the second period (2000 2007) with a corresponding increase in forest and agricultural lands (Table 5 and Fig. 5).

\section{Conclusions}

The land use changes observed over time in a region of Pindus mountain, central Greece, are likely due to both, the evolution of vegetation and socioeconomic factors. However, some changes to a limited extent are probably due to errors in the classification algorithm. This might be a result of the spectral similarity of land use classes. The gradual dominance of forests in mountainous areas is the result of the reduction of transhumance grazing, a fact that along with the good site quality, has favored the forest cover increase. The study and the continuous monitoring of land use cover in the Plastira municipality, region of Pindus mountain, in central Greece, is imperative for the coming years in order to obtain the scientific information necessary for proper land management in the area.

\section{Acknowledgements}

This work was funded by the Ministry of Education, under the Progamme "Environment - Archimedes II" and was carried out by the Department of Forestry in Karditsa,
Technological Education Institute of Larissa, Greece with collaboration of Dept. of Forestry and Natural Environment, Laboratory of Range Management, Aristotle University of Thessaloniki and the Forest Research Institute, NAGREF.

\section{References}

[1] Ainalis A., I. Meliadis, P. Platis and K. Tsiouvaras (2006).Classification and multitemporal monitoring of rangelands in the watershed of torrent Bogdana, prefecture of Thessaloniki: V.P. Papanastasis and Z.M. Parisi (eds), Rangelands in dry and warm areas. Proceedings of 5th Panhellenic Rangeland Congress. Heraklion, 1-3 November 2006. Greek Range and Pasture Society, Rep. No. 13, p. 221-226.

[2] Ainalis A., P. Platis, I. Meliadis, S.X. Papadopoulou, P. Sklavou and K. Tsiouvaras (2007). Monitoring of vegetation changes of rangelands in the watershed of torrent N. Apollonia, prefecture of Thessaloniki and the insect species which occur in the region. Proceedings of 13th Panhellenic Forestry Conference. Kastoria 7-10 October 2007. Volume II, p. 402-410.

[3] Athanassiou Z., B. Tantos, K. Tsiouvaras, P. Platis, A. Ainalis I. Meliadis, H. Karmiris and P. Sklavou (2007). Rangeland organization and development in semimountainous and mountainous ranges of Karditsa, Larissa, Magnesia Greece Create a system for monitoring implementation of Program Setting - Archimedes II 'Strengthening research groups in the Higher Technological Institute of Larissa, Final report p. 52. 
[4] Barntovas E. and I. Rantogianni - Tsiampaou (1983). Geological map of Greece (2nd edition). Institute of Geological and Mineral Research, Athens.

[5] Chavez P.S. and D. MacKinnon (1994). Automatic detection of vegetation changes in the southwestern United States using remotely sensed images. Photogrammetric Engineering and Remote Sensing, 60, pp. 571-583.

[6] Chouvardas D., I. Ispikoudis and V. Papanastasis (2006). Analysis of temporal changes in the landscape of the basin of Lake Koronia using GIS.Grasslands of lowland and semimountain areas: rural development lever (P. Platis, A. Sfougaris, T. Papachristou and A. Tsiontsis, eds). Proceedings of 4th Panhellenic Rangeland Congress, Volos, 10-12 November 2004. Greek Range and Pasture Society. Rep. No. 12 , p. $253-261$.

[7] Collins J. and C. Woodcock (1996). Explicit Consideration of Multiple Landscape Scales While Selecting Spatial Resolutions. Spatial Accuracy Assessment in Natural Resources and Environmental Sciences: Second International Symposium, USDA-Forest Service, Ft. Collins, CO.

[8] Dafis S. (1973). Classification of forest vegetation of Greece. Scientific Yearbook of Agriculture and Forestry School, Vol. IE, part B, Thessaloniki.

[9] H.N.M.S. (2013). Hellenic National Meteorological Service. Elements from Meteorological station of Kalambaka in central Greece.

[10] Holechek J.L., R.D, Pieper,. and C.H., Herbler (1989). Range management principles and practices. Prentice Hall Inc., USA.

[11] Kuntz S. and M. Karteris (1993). Fire risk modeling based on satellite remote sensing and GIS. In: "Satellite technology and GIS for Mediterranean forest mapping and fire management", International Workshop. Thessaloniki Greece, 4-6 November 1993 European Commission, pp. 165-177.

[12] Lillesand T.M. and R.W. Kiefer (1994). Remote sensing and image interpretation. Third Edition. John Willey and Sons Inc. $750 \mathrm{p}$.

[13] Mas J-F (1999). Monitoring land-cover changes: a comparison of change detection techniques. International Journal of Remote Sensing, 20 (1) :139-152.

[14] Mavrommatis G. (1980). The bioclima of Greece. Relations of climate and natural vegetation. Bioclimatic Map of Forest Research, Volume I (Appendix).

[15] Meliadis I., K. Radoglou and S. Kazantzidis (2004). Monitoring changes in habitat area of Special Protection Mountains Antichasia - Meteora using temporal digital satellite images. NAGREF - F.R.I., Thessaloniki, Independent issue, p. 61 .

[16] Meliadis I., P. Platis, A. Ainalis and M. Meliadis (2009). Monitoring and analysis of natural vegetation in a Special Protected Area of Mountain Antichasia - Meteora, central Greece. Environmental Monitoring and Assessment, 153 (1-4): $1-11$.

[17] Milchunas D.G. (2006). Responces of plant communities to grazing in the southwestern United States. Gen. Tech. Rep. RMRS-GTR-169. Fort Collins, CO: U.S. Department of Agriculture, Forest Service, Rocky Mountain Research Station, p.p. $35-37$.
[18] Nakos G. (1977). General Soil Map of Greece. Forest Research Institute of Athens.

[19] Noitsakis B., I. Ispikoudis, Z. Koukoura and V. Papanastasis (1992). Relation between successional stages and productivity in a mediterranean grassland. Proc. of Intern. Symp. in 'Natural Resource Development and Utilization', (CEC-DG12), Wageningen.

[20] Papanastasis V. (1989). Rangeland survey in Greece. Herba, 2:17-20.

[21] Papanastasis V.P. (1994). Grassland and Environment. Proceedings of the Workshop "Meadows and Rural Development". Greek Range and Pasture Society, No. 1, p. $71-81$.

[22] Papanastasis V.P. (2003). Ecology and Management of Subalpine Rangelands. In: P. Platis and T. Papachristou (eds), Rangeland and Development of Mountainous Areas. Proceedings of the 3rd Panhellenic Rangeland Congress. Karpenissi, 4-6 September 2002. Greek Range and Pasture Society, No. 10, p. 437-445.

[23] Perakis K., H. Beriatos and I. Gkeskou (1997). "Study of temporal changes characteristic of coastal areas of Magnesia in the last two decades based on maps and satellite images." 4th National Cartographic Conference, Cartography and Maps on the Promotion and Protection of the Environment, p. 103-111.

[24] Platis P., T. Papachristou and V. Papanastasis (2001). Possibilities of using the program inventory pasture management Prairie Region of Epirus. The Rangeland the threshold of the 21 st century (T. Papachristou and $O$. Dini-Papanastasi, eds). Proceedings of the 2nd Panhellenic Rangeland Congress. Ioannina, October 4-6 2000.Greek Range and Pasture Society. Rep. No. 9, p. 43-49.

[25] Platis P., I. Meliadis, T. Papachristou, D. Trakolis, S. Kazantzidis, K. Mantzanas, A. Makras, A. Dimalexis and S. Bourdakis (2004). Longitudinal monitoring of changes in habitat in the mountains Akarnanian using satellite images for sustainable management and protection. Final Report (Issue A) Program "Environmental Protection and Sustainable Development". E.T.ER.P.S. -, NAGREF - Forest Research Institute. Thessaloniki. Separate edition, p. 58.

[26] Platis P., A. Ainalis, I. Meliadis and K. Tsiouvaras (2009). Multitemporal monitoring of rangelands in the watershed of Vambakia, prefecture of Thessaloniki. Scientific Yearbook of the Department of Forestry and Environmental Management and Natural Resources, Democritus University of Thrace, Volume II, p. 167-176.

[27] Richards J.A. (1993). Remote Sensing Digital Image Analysis:An Introduction. Second Edition. Springer-Verlag, Berlin Heidelberg. p. 340.

[28] Sunar F. (1998). An analysis of changes in a multi-date data set: a case study in the Ikitelli area, Istanbul, Turkey. International Journal of Remote Sensing, 19 (2): 225-235.

[29] Wrbka T., K. Reiter and E. Szerencists (1999). Landscape structure derived from satellite images as indicator for sustainable land use. In: Operational Remote Sensing for Sustainable Development (Nieeuwenhuis, GJA, RAVaugham and M. Molenaar, eds), 18th EARseL symposium, p.119-127. 